\title{
Temperature-dependent growth of Antarctic krill: predictions for a changing climate from a cohort model
}

\author{
John Wiedenmann ${ }^{1,2, *}$, Kate Cresswell ${ }^{2}$, Marc Mangel ${ }^{2}$ \\ ${ }^{1}$ Department of Ocean Sciences, and ${ }^{2}$ Center for Stock Assessment Research (CSTAR), Department of Applied Mathematics \\ and Statistics, University of California, Santa Cruz, 1156 High St., Santa Cruz, California 95064, USA
}

\begin{abstract}
In the Southern Ocean, Antarctic krill Euphausia superba are the dominant prey item for many predators, and a changing climate may affect the biomass of krill available to both predators and the krill fishery. We projected growth trajectories for individual krill within cohorts and estimated how total biomass in an area available to both predators and the fishery may vary from year to year simply due to fluctuations in temperature. We used an existing temperature-dependent growth model and a time series of temperature data (1970 to 2004) for 2 regions in the Southern Ocean: (1) around the Antarctic Peninsula, and (2) around the island of South Georgia. The growth model predicted increasing individual size within a cohort (in terms of length and weight) with increasing temperature in the cooler Antarctic Peninsula region and decreasing individual size with increasing temperature in the warmer South Georgia region. Years with many cohorts of small individuals in the population resulted in biomass well below average, whereas years with many cohorts of large individuals resulted in biomass well above the average, suggesting that temporal changes in Southern Ocean temperatures may have profound effects on the total biomass in an area that is available to both predators and the fishery. Moreover, the effects of a potentially warming Southern Ocean on krill biomass will likely be more pronounced in the warmer regions occupied by krill.
\end{abstract}

KEY WORDS: Antarctic krill · Temperature-dependent growth $\cdot$ Biomass per recruit $\cdot$ Scotia Sea Resale or republication not permitted without written consent of the publisher

\section{INTRODUCTION}

In the Southern Ocean, Antarctic krill Euphausia superba are a species of primary importance, being the major prey of many species of birds, seals, whales, fish, and squid (Smetacek \& Nicol 2005). A fishery for krill developed in the early 1970s and has been the dominant fishery in the region since the late 1970s (Croxall \& Nicol 2004). Recently, concerns have been raised that catches will increase in part due to new harvesting and processing technologies that allow krill to be continuously pumped from the water and immediately processed, but also due to a likely increase in demand for krill in the near future as the demand for krill-based products, such as aquaculture feed or krill oil for human consumption, increases (Nicol et al. 2000).
The Southern Ocean krill fishery is managed by the Commission for the Conservation of Antarctic Marine Living Resources (CCAMLR), which has adopted an ecosystem-based, precautionary approach towards the krill fishery, taking into account its impact on krilldependent species (Reid et al. 2005). Annual catch limits are currently well below the estimated total krill biomass, limiting the potential for ecosystem-wide depletion of the krill resource. However, in many areas, the fishery operates in the main feeding grounds of breeding krill-dependent predators, such as seals and penguins (Croxall \& Nicol 2004). As a result, there is a potential for conflict between the fishery and the krill predators at a local scale.

Krill biomass fluctuates widely from year to year (Mackintosh 1972, 1973, Murphy et al. 1998), and the 
population sizes and breeding success of many krill predators are linked to local abundance of krill (Croxall et al. 1988, Reid \& Croxall 2001). Thus, for a better understanding of the potential conflicts between the fishery and krill predators, we must first identify all factors driving the variability in krill biomass.

The biomass of any species fluctuates in response to changes in mortality and reproductive success that affect the abundance of individuals in the population, as well as changes in growth that affect the weight of individuals in the population. Many studies have focused on determining the extent and sources of variability in abundance of krill (Siegel \& Loeb 1995, Loeb et al. 1997, Hewitt et al. 2003). The results from these studies indicate a link between regional abundance of krill and sea-ice extent in the previous winter. The suggested mechanism behind this relationship is that sea ice provides ice-algae for overwintering krill (particularly larvae), and sea ice may also facilitate the spring phytoplankton bloom, allowing for earlier spawning, which may also increase larval survival (Ross \& Quetin 1989, Hewitt et al. 2003, Nicol 2006). In addition, krill abundance has been negatively correlated with sea surface temperature (SST), although the mechanisms behind this relationship are not clear; SST may simply be an indicator of another mechanism, such as food availability or sea ice extent (Trathan et al. 2003, 2006).

In contrast to the numerous studies on variation in krill abundance and its effects on population biomass,

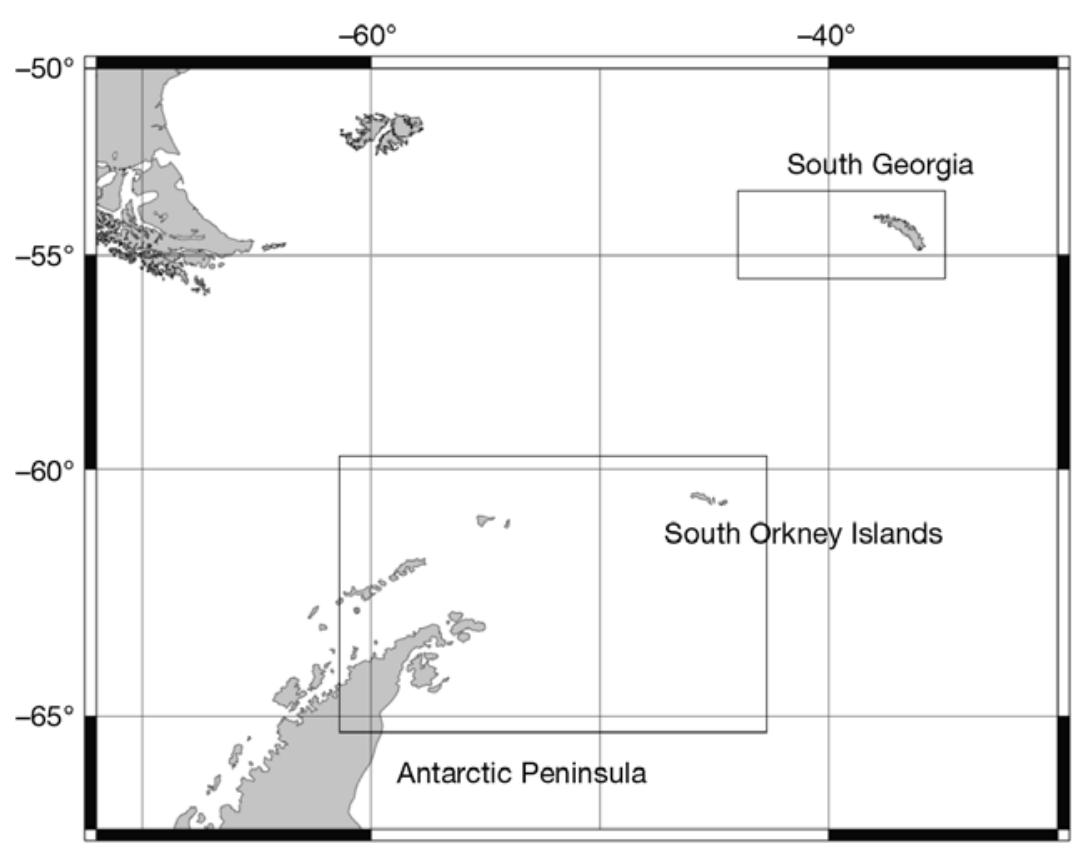

Fig. 1. South Atlantic sector of the Southern Ocean (created online via www. aquarius.geomar.de/omc/). Boxes around South Georgia and from the Antarctic Peninsula to the South Orkney Islands represent the approximate areas where we collected temperature data from the World Ocean Database no studies have explored how temporal changes in growth may also affect the biomass of the population. Krill are ectotherms, so changes in the temperature of the Southern Ocean will surely affect their growth rates. Based on other Antarctic ectotherms, we might expect extreme sensitivity of krill to temperature (Peck et al. 2004).

There has been a significant warming trend over Antarctica over the past $50 \mathrm{yr}$ (Vaughan 2003), but the trend for the Southern Ocean over the same period is less clear. Meredith \& King (2005) showed rapid warming $\left(>1^{\circ} \mathrm{C}\right)$ of summer surface waters west of the Antarctic Peninsula over the last $50 \mathrm{yr}$, but little warming or even a slight cooling in summer surface waters east of the Antarctic Peninsula and in the Scotia Sea over the same time period. Levitus et al. (2005) showed slight warming in most waters between 65 and $75^{\circ} \mathrm{S}$ latitude, but also a slight cooling in some surface waters (above $650 \mathrm{~m}$; see Jacobs 2006 for a review of changes in the Southern Ocean). From these studies, it is clear that temporal changes in Southern Ocean temperature are not uniform across the entire ocean, or even throughout the water column.

Attempts to forecast the impacts of climate change on organisms have often focused on broad scale patterns across ecosystems (e.g. Behrenfeld et al. 2006, Botkin et al. 2007). However, for more accurate predictions, one must consider the biology of individual species and explore how it may change as the climate changes. In this study, we examined the impacts of temporal change in Southern Ocean temperatures on the growth of Antarctic krill. Using an existing temperaturedependent growth model and a time series of temperature data, we projected the growth trajectories for individual cohorts and estimated how total biomass in an area available to both predators and the fishery may vary from year to year. Specifically, we used temperature data obtained from the World Ocean Database (WOD) for 2 regions in the South Atlantic sector of the Southern Ocean: around the island of South Georgia, and from the Antarctic Peninsula east to South Orkney islands (Fig. 1). We selected these regions because they contain some of the highest concentrations of krill in the Southern Ocean (Atkinson et al. 2004, Siegel 2005), and because they represent 2 different environments, with South Georgia being the northernmost, and therefore the warmest, area inhabited by krill. 


\section{MATERIALS AND METHODS}

Growth models. Although a number of krill growth models have been developed, few project growth as a function of temperature. Three models project some aspect of growth as a function of temperature (Alonzo \& Mangel 2001, Atkinson et al. 2006, Candy \& Kawaguchi 2006), with a fourth model (Hofmann \& Lascara 2000) modified by Fach et al. $(2002,2006)$ to incorporate temperature dependence. We used only the model developed by Atkinson et al. (2006), and defer explanation of our exclusion of the other models to the Discussion. The model of Atkinson et al. (2006) is based on the instantaneous growth rate (IGR) method, which uses field estimates of growth increment and intermolt period (IMP) to project krill growth.

General model structure. We used the growth model to project growth in terms of length, but also weight (using the length-weight relationships from Hofmann \& Lascara 2000; Table 1), and how it may vary temporally and with temperature. We also needed to account for temperature differences in habitats occupied by krill. Krill commonly exhibit diurnal vertical migration, moving toward the surface at night (Watkins 2000). Thus, krill may experience different temperatures based on the regions of the water column occupied in a given day. Therefore, we projected krill growth in daily time steps, and assumed that they spend a proportion $(\tau[t])$ of each day in a deep habitat and a proportion $(1-\tau[t])$ in a shallow habitat (cf. Alonzo \& Mangel 2001).

Temperature. We obtained temperature profile data for 1970 to 2004 from the WOD (www.nodc.noaa.gov/ OC5/indprod.html) for the waters around South Georgia (43 to $34^{\circ} \mathrm{W}, 52.5$ to $56^{\circ} \mathrm{S}$ ) and for the waters from the Antarctic Peninsula to the South Orkney Islands (62 to $42^{\circ} \mathrm{W}, 59$ to $66^{\circ} \mathrm{S}$; Fig. 1). Although the time

Table 1. Length to wet weight relationships for different size classes of krill. Length estimates in the model are for total length $(L)$ and must be converted to standard length $\left(L_{\mathrm{S}}\right)$ to estimate wet weight

\begin{tabular}{|c|c|c|c|}
\hline Eq. & $\begin{array}{l}\text { Size range } \\
\quad(\mathrm{mm})\end{array}$ & Description & Source \\
\hline$W(t)=0.0470 L_{\mathrm{S}}(t)^{2.121}$ & $2-5$ & $\begin{array}{l}\text { Wet weight } \\
\text { (mg) }\end{array}$ & Ikeda (1984) \\
\hline$W(t)=0.0072 L_{\mathrm{S}}(t)^{3.021}$ & $10-40$ & $\begin{array}{l}\text { Wet weight } \\
(\mathrm{mg})\end{array}$ & $\begin{array}{l}\text { Hofmann \& Lascara } \\
(2000)\end{array}$ \\
\hline$W(t)=0.0016 L_{\mathrm{S}}(t)^{3.423}$ & $40-60$ & $\begin{array}{l}\text { Wet weight } \\
(\mathrm{mg})\end{array}$ & $\begin{array}{l}\text { Hofmann \& Lascara } \\
(2000)\end{array}$ \\
\hline$L_{\mathrm{S}}(t)=\frac{L(t)-0.971}{1.001}$ & & $\begin{array}{l}\text { Conversion of total } \\
\text { length }(L) \text { to standard } \\
\text { length }\left(L_{\mathrm{S}} \text { both in } \mathrm{mm}\right)\end{array}$ & Miller (1983) \\
\hline
\end{tabular}

step of our model was $1 \mathrm{~d}$, acquiring temperature data at that resolution is not practical. We therefore generated monthly averages for each region. In total, we analyzed 4785 and 9728 depth-temperature profiles to generate monthly temperature averages for each year over the South Georgia and Antarctic Peninsula regions, respectively. There were many instances, particularly over the winter months, for which no data were available. When an average was not available for a given month in a particular year, we used the mean temperature for that month (calculated across all available years).

To account for the vertical migration of krill, we divided each temperature profile into $50 \mathrm{~m}$ sections down to $300 \mathrm{~m}$, and calculated the average monthly temperature for each region in the water column. Based on the seasonal variation in vertical migration (Siegel 2005), we assumed the following distributions for age-1 and older krill. In summer (January to March) krill occupy surface waters (0 to $50 \mathrm{~m}$ ) during both day and night $(\tau[t]=0)$. In the spring (October to December) and in the fall (April to June), krill occupy waters between 100 and $150 \mathrm{~m}$ during the day $(\tau[t]>0)$, and move up to the region between 50 and $100 \mathrm{~m}$ at night. Finally, during the winter (July to September), krill spend the day between 250 and $350 \mathrm{~m}$ and migrate up to the region between 100 and $150 \mathrm{~m}$ at night. We assumed that age-0 krill depend solely on phytoplankton and therefore occupy surface waters (0 to $50 \mathrm{~m}$ ) completely during their first year of life.

Food input. In the growth model, IMP depends only on temperature (Eq. 2 below) but the amount of growth following a molt depends on temperature, pre-molt length, and food (Eq. 5 below). Atkinson et al. (2006) and Tarling et al. (2006) did not measure the amount of food ingested by krill; rather, they measured surface chlorophyll (chl) concentrations (in $\mathrm{mg} \mathrm{chl} \mathrm{a} \mathrm{m}^{-3}$ ) in the area where krill were collected and correlated the growth increment with ambient phytoplankton concentrations, not the food ingested. In their experiments, krill were starved after collection so that their results must be modified to apply them to krill growing with a more or less continuous source of food. For example, we initially parameterized the model using SeaWiFSderived estimates of phytoplankton concentrations in each region, but the resulting growth curves were unreasonable: krill around the Antarctic Peninsula grew too slowly or not at all in the first year, while krill around South Georgia grew too rapidly in the first year, nearly reaching asymptotic 
size. Furthermore, the low phytoplankton concentrations in the winter in both regions resulted in shrinkage of $10 \mathrm{~mm}$ or more for adult krill.

Thus, some modification of the model of Atkinson et al. (2006) was required. We could modify the coefficients of the model (in Eq. 5 below), the food input, or both; here we chose to modify the food input. In particular, to focus attention on the influence of temperature on krill growth, we set temporal patterns of food to produce growth curves in each region similar to those of Siegel (1987). We generated a reference growth curve following Siegel (1987) such that growth is minimal between May and September, and starting length at age- 0 is $2 \mathrm{~mm}$ and length at age -1 is $22 \mathrm{~mm}$ (we discuss the reason for these length constraints below). By minimizing the sum of squares, we numerically solved for the monthly food concentrations that produced a growth curve that most closely matched the reference for a cohort experiencing average temperatures throughout its life. Food availability varies by month, but each cohort experiences the same food concentrations to keep the impact of food on growth constant across all cohorts.

The growth model. Krill grow through a series of molts. The IGR method accounts for growth during discrete periods by measuring the IMP and the amount of growth that occurred during a molt (Quetin \& Ross 1991, Nicol et al. 1992). The general IGR growth formula is:

$$
L(t+1)=L(t)+L(t) \times \delta \times G(t)
$$

where $G$ is the growth increment, measured as the proportion of post-molt length, $L(t+1)$ to pre-molt length, $L(t)$, and $\delta$ is an indicator function that takes a value of 1 if $t$ corresponds to a molt, or a value of 0 if it does not. Although there is a general pattern of increasing size of ectotherms at lower temperatures (Atkinson \& Sibly 1997), we know of no studies showing different maximum sizes in krill based on temperature, so we set maximum length at $60 \mathrm{~mm}$ for both regions (Siegel 1987).

There are 2 models for predicting the IMP of krill as a function of temperature. Kawaguchi et al. (2006) estimated IMP only as a function of temperature, while Tarling et al. (2006) estimated IMP as a function of temperature, length, sex, and maturity. The IMP model of Kawaguchi et al. (2006) predicts a decrease in IMP with increasing temperature; the model of Tarling et al. (2006) predicts opposing trends in IMP for male and female krill with increasing temperature. We explored both IMP models, but used the model of Kawaguchi et al. (2006) for simplicity because it does not require distinguishing between sexes and maturity stages. IMP (in days) is:

$$
\mathrm{IMP}=\exp \left\{\alpha_{0}+\alpha_{1} \times \ln [T(t)+2]\right\}
$$

where $\alpha_{0}$ and $\alpha_{1}$ are constants (Table 2), and $T(t)$ is the average of the day and night habitat temperatures, $T_{\mathrm{d}}(t)$ and $T_{\mathrm{n}}(t)$, respectively, adjusted for the amount of time spent in each habitat:

$$
T(t)=\tau(t) \times T_{\mathrm{d}}(t)+[1-\tau(t)] \times T_{\mathrm{n}}(t)
$$

With an estimate of the IMP, we can calculate the exact day on which a molt occurs, using the method outlined by Candy \& Kawaguchi (2006). Fractional development at time $t(d[t])$ is calculated by:

$$
d(t)=\sum_{s=1}^{s=t_{\max }} \frac{1}{\operatorname{IMP}(s)}
$$

Molts occur when $d(t)$ is closest to a set of integers corresponding to molt number, $i=1,2, \ldots I$, where $I$ is the total possible number of molts in a lifetime for an individual krill. Therefore, the first molt $(i=1)$ occurs on Day $t$, where $d(t)$ is closest to 1 . Knowing the days on which molts occur, we then estimate $G$ as a function of length, temperature, and food concentration $f(t)$, using:

$G_{I}(t)=\beta_{0}+\beta_{1} L(t)+\beta_{2} L(t)^{2}+\frac{\beta_{3} f(t)}{\beta_{4}+f(t)}+\beta_{5} T(t)+\beta_{6} T(t)^{2}$

where $\beta_{0}$ to $\beta_{6}$ are constants. Atkinson et al. (2006) provided parameter estimates for both male and female krill of different developmental stages. We explored all parameterizations, but only report the results for all stages and sexes combined (Table 2).

Biomass per recruit. Biomass per recruit (BPR) is the expected mass of an individual recruit, averaged over the age of death, and is commonly used in fisheries to determine the effects of harvest rate on the contribution of a cohort (Quinn \& Deriso 1999, Haddon 2001, Mangel 2006). Here, we used BPR to determine the effects of water temperature on krill size (in weight)

Table 2. Parameter values used in the instantaneous growth rate (IGR) model, as estimated by Kawaguchi et al. (2006) and Atkinson et al. (2006)

\begin{tabular}{|ccc|}
\hline Eq. & Parameter & Value \\
\hline 2 & $\alpha_{1}$ & 3.5371 \\
& $\alpha_{0}$ & -0.5358 \\
5 & $\beta_{0}$ & 6.6 \\
& $\beta_{1}$ & -0.385 \\
& $\beta_{2}$ & 0.00259 \\
& $\beta_{3}$ & 17.53 \\
& $\beta_{4}$ & 0.332 \\
& $\beta_{5}$ & 0.595 \\
& $\beta_{6}$ & -0.477 \\
\hline
\end{tabular}


and thus biomass available to predators and the krill fishery. Using monthly temperature estimates from 1970 to 2004 and the growth model, we estimated BPR for cohorts around the Antarctic Peninsula and South Georgia. Krill longevity has been estimated to be as high as 9 yr (Nicol 2006); to be more conservative, we assumed a maximum age of 5 yr. Around the Antarctic Peninsula, all age classes of krill can be found (age-0 through age-5), and we therefore assumed that age-0 krill recruit to the region at a length of $2 \mathrm{~mm}$ (Hofmann \& Lascara 2000). As a result, we only estimated BPR for Antarctic Peninsula cohorts from 1970 to 1999. We could not estimate BPR for a cohort produced after 1999 because these cohorts may still have been alive in 2004 (the final year with temperature data). Around South Georgia, age-0 krill are absent. We thus explored 2 possibilities for cohorts around South Georgia: (1) that age-1 krill recruit to the region at a constant length of $22 \mathrm{~mm}$ (Watkins et al. 1999) and (2) that length at recruitment to age-1 varies based on variation in length at age-1 around the Antarctic Peninsula, on the assumption that young krill are transported from there to South Georgia (Hofmann et al. 1998, Fach et al. 2002, Tarling et al. 2007). For example, if the 1970 cohort around the peninsula reaches a length of $20 \mathrm{~mm}$ at the end of the first year, we set the starting length of 1971 cohort around South Georgia to $20 \mathrm{~mm}$. Therefore, we estimated BPR for cohorts around South Georgia from 1970 to 2000 and from 1971 to 2000 for cohorts with constant and varying starting lengths, respectively. Again, we could not estimate BPR for a cohort produced after 2000 around South Georgia because these cohorts may still have been alive in 2004 .

To estimate BPR, we need an estimate of the abundance of a cohort that recruits to the population in Year $y$

$N(t \mid y)=$ number of krill on Day $t$ (post recruitment) from a cohort that recruits:

$$
\text { on Day } 1 \text { in Year } y
$$

Assuming constant recruitment, $R$, of a cohort to the population, we have:

$$
\begin{aligned}
& N(t \mid y)=R \quad \text { for } t=1 \\
N(t \mid y)= & N(t-1 \mid y) \times\left(\mathrm{e}^{-M-F}\right) \quad \text { for } t>1
\end{aligned}
$$

where $R$ is set to 1000 for all $y$, and $M$ and $F$ are the instantaneous rates of natural and fishing mortality, respectively. We set $M$ to 0.0025 based on the range of values presented by Siegel (2000), representing a loss of approximately $0.25 \% \mathrm{~d}^{-1}$ or $60 \% \mathrm{yr}^{-1}$. The number of individuals of cohort $y$ dying on Day $t$ $\left(N_{\mathrm{D}}[t \mid y]\right)$ is:

$$
N_{\mathrm{D}}(t \mid y)=N(t \mid y) \times\left(1-\mathrm{e}^{-M-F}\right)
$$

If the mass of an individual of cohort born in Year $y$ at time of death $t$ is $W(t \mid y)$, then the BPR for the cohort born in Year $y$ is:

$$
\operatorname{BPR}(y)=\frac{1}{R} \sum_{t=1}^{t=t_{\max }} \frac{M}{F+M} \times N_{\mathrm{D}}(t \mid y) \times W(t \mid y)
$$

where $\frac{M}{F+M}$ is the fraction of those dying by natural mortality (see Mangel 2006). By incorporating $F$ into the calculation, we can explore a range of values to determine a suitable harvest given the influence of temperature on BPR of a cohort.

We estimated krill growth trajectories for cohorts in each region starting on 1 January and projected for $6 \mathrm{yr}$ around the Antarctic Peninsula, and for $5 \mathrm{yr}$ around South Georgia.

Total biomass. Estimates of BPR tell us how growth of a particular cohort has varied in response to temperature. The existence of a multiple cohorts with belowor above-average BPR may have dramatic effects on the total biomass in an area available to both predators and the fishery. On any Day $t$, the biomass $B$ of cohort born in Year $y$ is:

$$
B(t \mid y)=N(t \mid y) \times W(t \mid y)
$$

and the total biomass in the population in Year $z$ is:

$$
B_{\text {total }}(t \mid z)=\sum_{V=z-x}^{z} B(t \mid y)
$$

where $x$ is the maximum number of cohorts in the population at any one time $(x=6$ for the Antarctic Peninsula and $x=5$ for South Georgia), and $v$ represents the year in which the oldest cohort remaining in the population was born.

\section{RESULTS}

\section{Temperature}

Around the Antarctic Peninsula, temperatures in the depths of water column occupied by krill ranged from -1.87 to $2.66^{\circ} \mathrm{C}$. Around South Georgia, temperatures were as low as $-0.86^{\circ} \mathrm{C}$ and as high as $5.4^{\circ} \mathrm{C}$. In Fig. 2, we show the annual mean temperature experienced by krill in waters around the Antarctic Peninsula and South Georgia from 1970 to 2004. For the Antarctic Peninsula, the temperature experienced by krill depends on age, since we assumed that age- 0 krill occupy the surface layer for the entire year, while age-1+ occupy different sections of the water column throughout the year. The trends in annual mean temperatures experienced by age- 0 and age-1+ krill mirrored one another, with age-0 krill exposed to slightly higher temperatures each year. Notably, there 


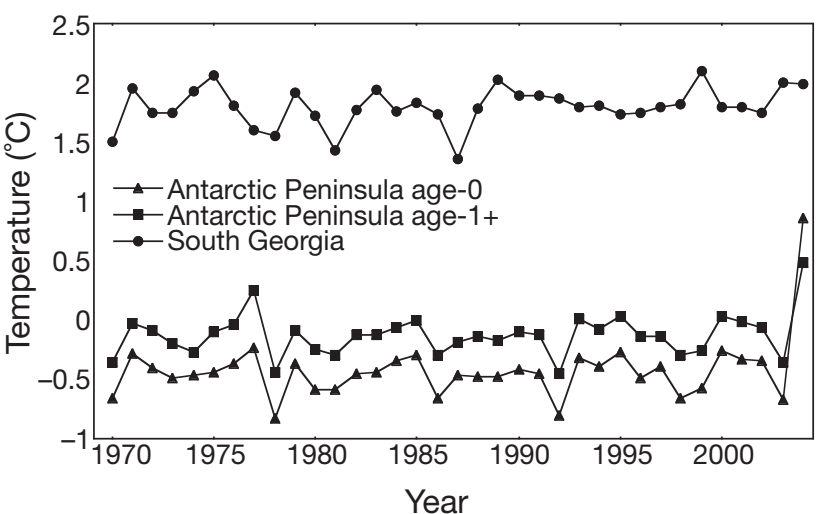

Fig. 2. Average annual temperatures for the habitats occupied by krill in waters off South Georgia and the Antarctic Peninsula. For the Antarctic Peninsula region, the average temperature krill experience depends of their age, since we assumed age-0 krill occupy surface waters, while age-1 krill exhibit extensive vertical migration

was no warming or cooling trend apparent in the time series, although 2004 temperatures were anomalously high. There was also no apparent trend in temperatures around South Georgia, although annual temperatures showed considerably wider fluctuations prior to 1989, and have remained relatively stable since then (Fig. 2).

\section{Food}

Food concentrations that produce growth curves matching those of Siegel (1987) for average temperature around the Antarctic Peninsula were much higher in the first 14 mo than around South Georgia or around the Antarctic Peninsula for the remainder of life (Fig. 3a). After $14 \mathrm{mo}$, the predicted food concentrations began to follow an annual cycle (Fig. 3b), but the peaks occurred in different months in each region. For the Antarctic Peninsula, the highest food concentrations were from September through November, whereas for South Georgia they are highest from January through March. Although food concentrations were much higher for the first 14 mo of life around the Antarctic Peninsula (average for the first $14 \mathrm{mo}=$ $4.6 \mathrm{mg} \mathrm{chl} \mathrm{a} \mathrm{m}{ }^{-3}$ compared to $0.25 \mathrm{mg} \mathrm{chl} \mathrm{a} \mathrm{m}^{-3}$ for the remaining months) these values were well within the range of concentrations observed by Atkinson et al. (2006), i.e., between 0 and $12 \mathrm{mg}$ chl a m $\mathrm{m}^{-3}$ ).

\section{Mean growth}

For months where krill occupy both a shallow and deep habitat (April to December), we explored a range of $\tau(t)$ from 0 to 1 to examine the influence of different

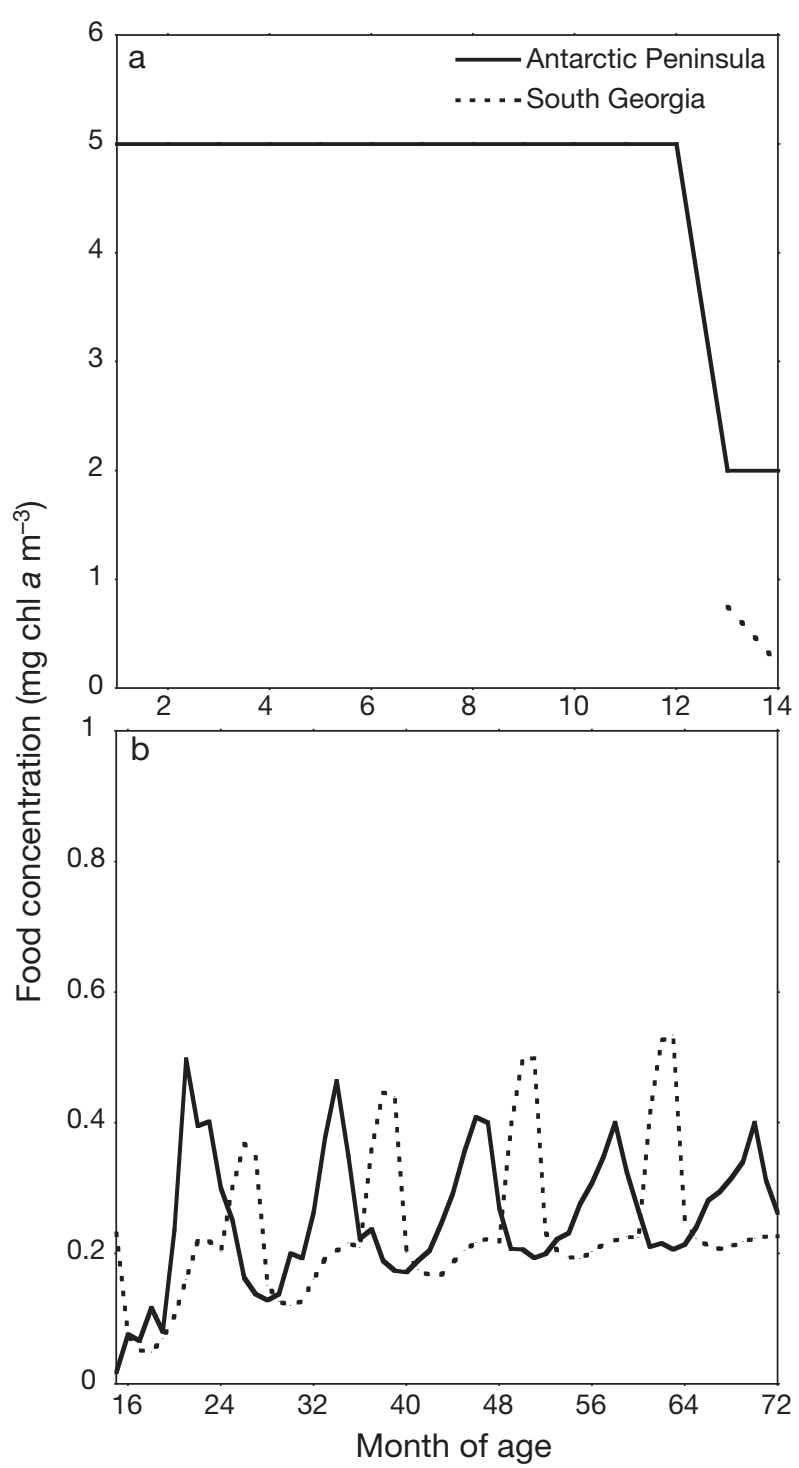

Fig. 3. Monthly food concentrations in the growth model required to produce growth curves matching those of Siegel (1987) for average temperature. (a) The first 14 mo of life; (b) the remaining months of life. We assumed that age-0 krill are absent around South Georgia, so do not present food concentrations for Months 1 to 12 for this region

times spent in each habitat on mean growth. Changing $\tau(t)$ did not substantially change our results, and we therefore only present results for $\tau(t)=0.5$ for April through December in both regions.

Because cohorts from the Antarctic Peninsula had a much smaller starting length than cohorts from South Georgia, BPR estimates were much smaller. In the absence of fishing $(F=0)$, BPR estimates for the Antarctic Peninsula cohorts ranged from 99 to $171.9 \mathrm{mg}$ (Fig. 4), corresponding to lengths of 23.5 and $28.1 \mathrm{~mm}$, respectively. Furthermore, there was no trend in BPR over the time series. BPR estimates around South 


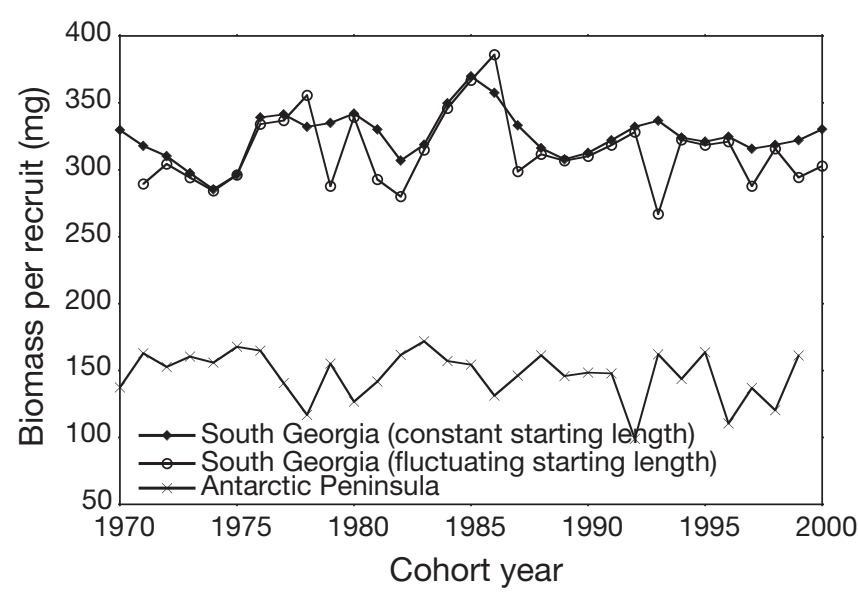

Fig. 4. Biomass per recruit (BPR) for the region off the Antarctic Peninsula from 1970 to 1999 and South Georgia from 1970 to 2000. Here we assumed $F=0$ in Eqs. (8) \& (9)

Georgia cohorts with a constant starting length ranged from 285.5 to $369.8 \mathrm{mg}$ (mean length between 33.4 and $36.3 \mathrm{~mm}$; Fig. 4). When starting length was varied around South Georgia, the range of BPR estimates was greater, ranging from 267 to $386.2 \mathrm{mg}$ (length range from 32.5 to $36.8 \mathrm{~mm}$ ). There was also no trend over the time series in this region. In Fig. 5, we plotted length trajectories for the smallest, largest, and average cohorts (in terms of BPR) for each region to show how growth trajectories vary in extreme cases.

To understand how temperature affects predictions of BPR, BPR must be plotted against the temperatures that a cohort experiences in its lifetime. Because BPR is a balance between growth and mortality, not all temperatures that a cohort experiences may affect estimates of BPR, particularly temperatures experienced later in life when growth is greatly reduced and there are very few members of the cohort remaining. There- fore, we calculated the temperature that a cohort experiences $(\bar{T})$ in Year 1, Years 1 and 2, and so on until all years (1 to 5 for South Georgia, 1 to 6 for the Antarctic Peninsula) were used in the calculation:

$$
\bar{T}=\frac{1}{t_{\max }} \sum_{t=1}^{t=t_{\max }} \tau(t) \times T_{\mathrm{d}}(t)+[1-\tau(t)] \times T_{\mathrm{n}}(t)
$$

where $t_{\max }$ is the total number of days (e.g. $t_{\max }=365$ when calculating the temperature experienced in Year 1 , and $t_{\max }=730$ when calculating the temperature in Years 1 and 2). We performed a linear regression of BPR against the range of temperatures, and selected the $\bar{T}$ that resulted in the best fit (determined by the highest $\mathrm{R}^{2}$ value). For both regions, the temperature for Years 1 to 3 was the best predictor of BPR, indicating that temperature has the largest effect on growth (and BPR) in the first 3 yr of life.

The model predicted that in the Antarctic Peninsula region, as temperature increases, BPR increases, with a predicted increase of $175.9 \mathrm{mg}$ per ${ }^{\circ} \mathrm{C}(95 \% \mathrm{CI}$ 119.4 to 232, $\mathrm{p}<0.0001$; Fig. 6). Comparing the influence of temperature on BPR around South Georgia (with constant starting length) revealed a different picture. The model predicted a decrease in BPR with increasing temperature, with a predicted decrease of $131.7 \mathrm{mg}$ per ${ }^{\circ} \mathrm{C}(95 \% \mathrm{CI}-82.6$ to -180.9 , p < 0.0001 ; Fig. 6). We did not perform this analysis for South Georgia with fluctuating starting lengths because the relationship between $\mathrm{BPR}$ and temperature became obscured due to the differing effects of temperature in each region.

Increased mortality from fishing will decrease the BPR of a cohort. However, as we have already shown, temperature may have a large influence on the BPR, so different harvest rates may produce the same BPR for different cohorts. As an example, in Fig. 7 we plotted
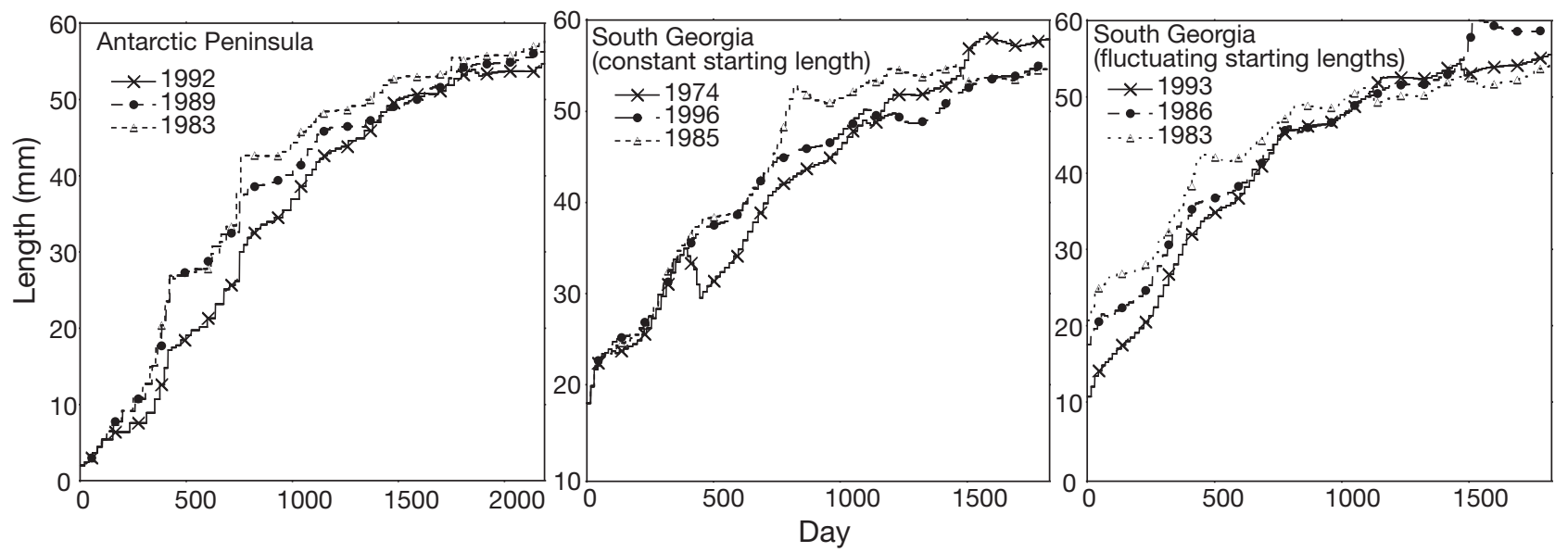

Fig. 5. Length trajectories (in daily time steps) of the largest, smallest, and average-sized cohorts (in terms of BPR) predicted for the Antarctic Peninsula and South Georgia, with constant and varying lengths 


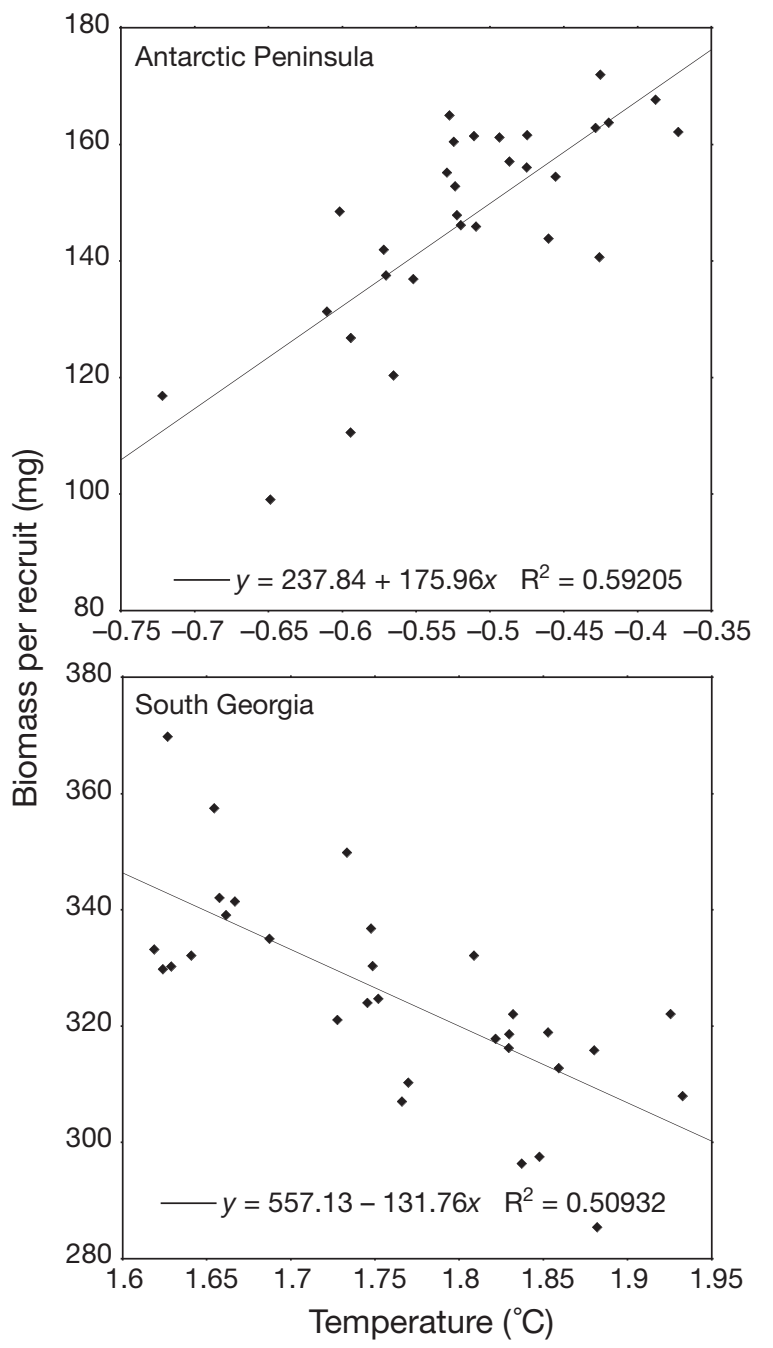

Fig. 6. BPR vs. average temperature that a cohort experiences in the first $3 \mathrm{yr}$ of life for the Antarctic Peninsula and South Georgia (constant starting length)

BPR as a function of $F$ for cohorts with the smallest, average, and largest BPR from the South Georgia region (constant starting length). For these 3 cohorts, the same BPR could be produced by very different harvest rates $(F=0.15,0.35$, and 0.48 for the smallest, average, and largest cohorts, respectively; Fig. 7).

\section{Total biomass}

Estimates of BPR exhibited serial autocorrelation in both regions (Fig. 4). Therefore, these periods of below or above average cohort BPR may have an effect on the total biomass in the region. For each year, we had estimates of abundance for all cohorts in the population from Eq. (7), and we could estimate the total biomass in a given year using Eq. (11). Because recruitment and

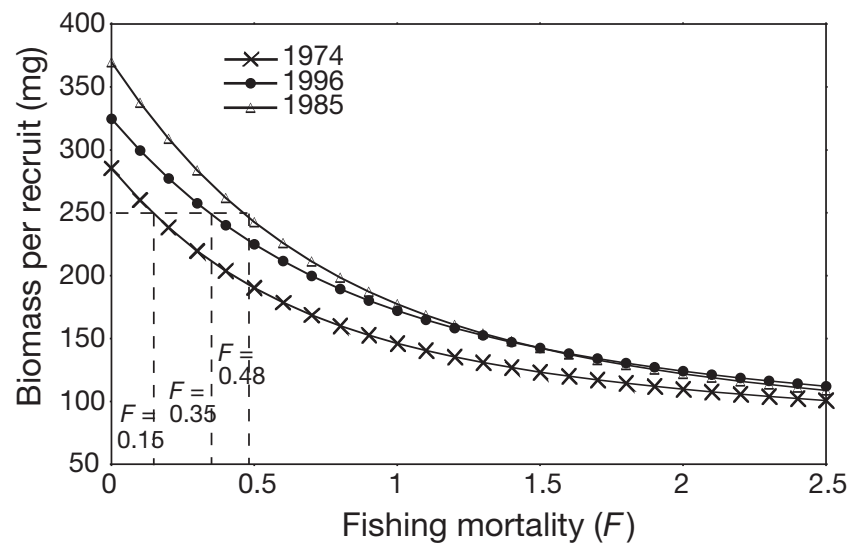

Fig. 7. BPR as a function of fishing mortality rate, $F$, for the largest, smallest, and average-sized cohorts around South Georgia (constant starting length)

mortality were constant for all cohorts, total abundance in the population was constant across all years. As a result, changes in total biomass were solely the result of differential growth for the different cohorts, resulting from different temperatures experienced throughout ontogeny. Because our estimate of biomass was relative, depending on the initial level of recruitment, we present the results relative to the mean biomass for the time period. For the Antarctic Peninsula, total biomass ranged from $20 \%$ below average to $40 \%$ above average. For South Georgia, when cohorts had a constant starting length, total biomass ranged from $29 \%$ below average to $17.5 \%$ above. Total biomass was very similar around South Georgia when starting length fluctuated, ranging from $28 \%$ below to $19 \%$ above average. There was no discernable trend in total biomass in each region over the time series, although wider fluctuations occurred after 1990 around the Antarctic Peninsula, whereas wider fluctuations occurred prior to 1990 around South Georgia (for both model runs; Fig. 8).

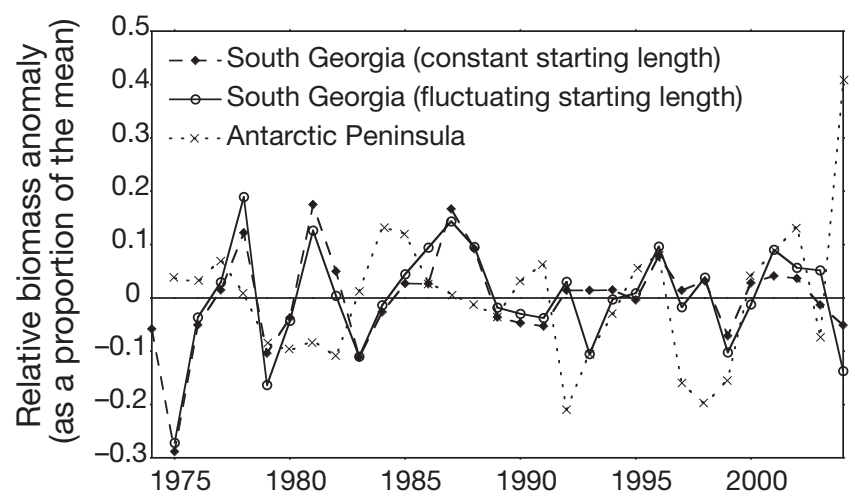

Fig. 8. Total relative biomass anomaly (measured as a proportion of the mean) from 1975 to 2004 for the Antarctic Peninsula and from 1974 to 2004 for South Georgia. The line at 0 represents the mean relative biomass 


\section{Climate change}

From Fig. 6 it is apparent that a warming Southern Ocean will have different effects on krill growth, with an increase in BPR in the cooler Antarctic Peninsula region and a decrease in BPR in the warmer waters off South Georgia. However, the impacts of a warming Southern Ocean on krill BPR may be mitigated by changes in food availability. For example, around South Georgia, an increase in food availability may lessen or even prevent decreases in BPR if temperature increases. To determine the impacts that a warming ocean and variable food availability may have on BPR, we first estimated BPR for an 'average' cohort in each region (with constant starting lengths) using the food concentrations shown in Fig. 3 and the average monthly temperature from 1970 to 2004 in each region. We could then explore how a range of food (from -100 to $+100 \%$ ) may affect BPR over a range of temperature increases (from 0 to $5^{\circ} \mathrm{C}$ for the Antarctic Peninsula and from 0 to $2^{\circ} \mathrm{C}$ for South Georgia). In Fig. 9, we show the balance between changes in food availability and increasing temperature. For the Antarctic Peninsula, contour lines (representing the same proportional change in BPR) decreased up to an increase in temperature of 2.5 to $3^{\circ} \mathrm{C}$, and then increased sharply after that. This indicates that after an increase in this region of about $3^{\circ} \mathrm{C}$, increasing temperature will begin to have a negative impact on BPR (for a given level of food availability). Conversely, around South Georgia, contour lines increased over the range of temperature increases. To maintain a constant BPR in this region with a warming ocean, more food will be required. For example, if waters off South Georgia warm by $1^{\circ} \mathrm{C}$, an increase in food of approximately $40 \%$ will be needed to keep BPR the same.

\section{DISCUSSION}

Temporal changes in water temperature affect the growth of individuals within a cohort, which, in turn, may affect total biomass in a region. Our examination shows different effects of temperature in the regions explored. For the Antarctic Peninsula region, the growth model predicts increasing individual size with increasing temperature. Conversely, a decrease in individual size with increasing temperature is predicted in the South Georgia region. The reasons for the different predictions between regions are clear. The IMP model (Kawaguchi et al. 2006) predicts decreasing IMP with increasing temperature, and the growth increment model (Atkinson et al. 2006) follows a parabolic relationship with temperature reaching a maxi-

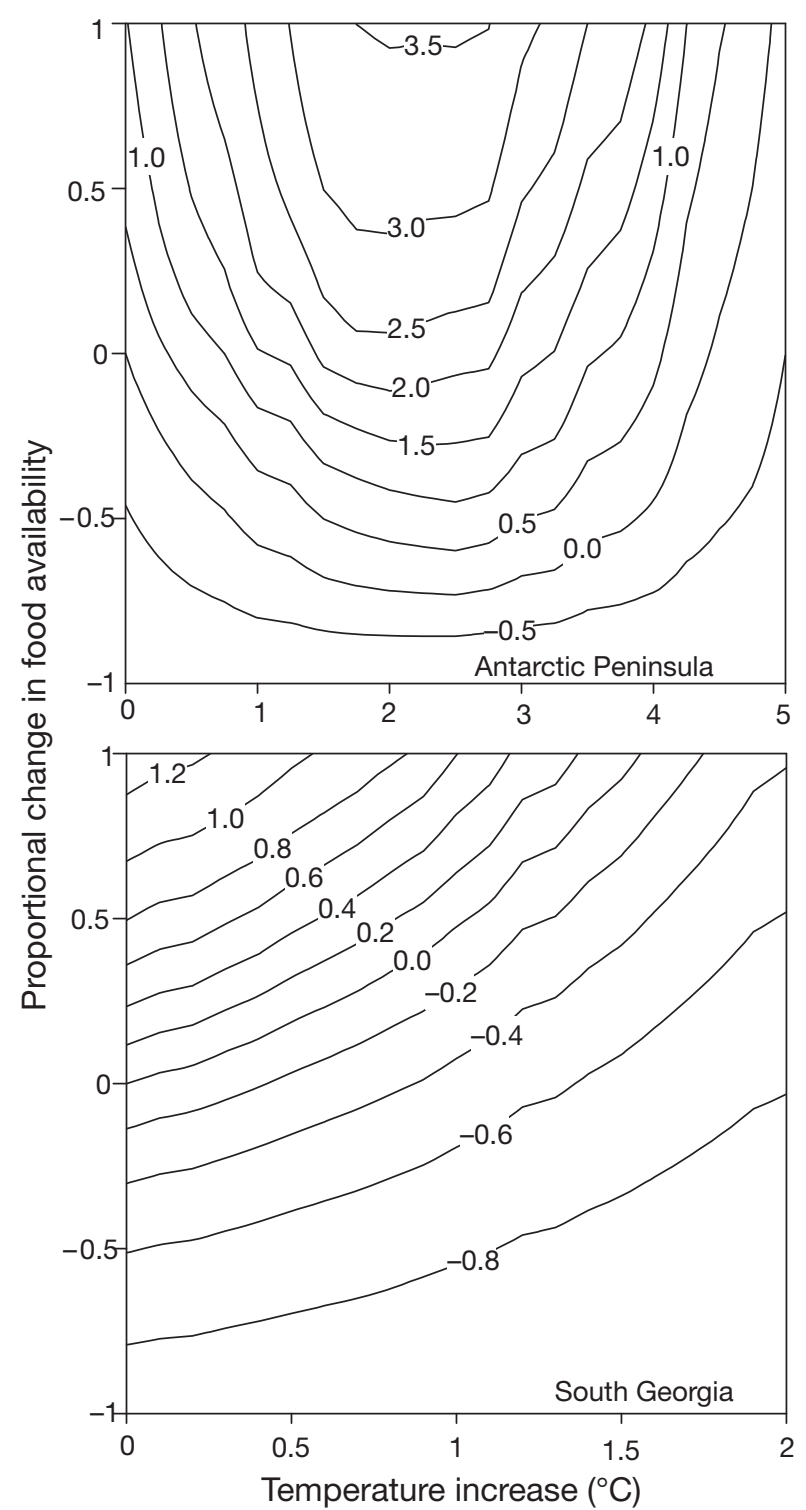

Fig. 9. Proportional changes in BPR (shown by the contour lines) resulting from proportional changes in food availability and increasing temperature for the Antarctic Peninsula and South Georgia (constant starting length)

mum at about $0.6^{\circ} \mathrm{C}$ (computed from the parameters in Table 2). Therefore, mean growth increases with rising temperature in the colder waters off the Antarctic Peninsula and decreases with rising temperatures in the warmer waters off South Georgia, where the increased number of molts is not sufficient to offset the decrease in growth.

The parabolic relationship between temperature and growth also explains why the food concentrations we estimated to produce reasonable growth curves peaked in October in the Antarctic Peninsula and in February in South Georgia (Fig. 3). The reference 
growth curve we created to estimate food concentrations allows for little or no growth from May through September, so rapid growth must occur in the remaining months. In both regions, the warmest temperatures occurred between January and March, but around the Peninsula, these temperatures are close to the optimal temperature for maximizing growth (between 0.7 and $1.0^{\circ} \mathrm{C}$ ), whereas they are much higher than the optimal temperature around South Georgia (between 3.0 and $3.5^{\circ} \mathrm{C}$ ). Conversely, in October and November, temperatures are close to optimal off South Georgia but are well below optimal off the Antarctic Peninsula. As a result, the sub-optimal temperatures for South Georgia in January through March and for the Peninsula in October and November mean that higher food concentrations are needed in these months to allow for enough growth during the limited growing season.

Predictions from both regions show that changes in temperature may have relatively small effects on the individual length of members of a cohort, but these small changes can have a large impact on the total biomass in a region. In the Antarctic Peninsula region, successive cohorts with individuals of below or above average BPR result in total biomass ranging from $20 \%$ below to $40 \%$ above average. Around South Georgia, successive cohorts with below average BPR result in biomass well below average (as low as $29 \%$ below the mean), whereas many cohorts with above average BPR result in biomass well above the average (as much as $19 \%$ higher; Fig. 8). Thus, temporal changes in Southern Ocean temperatures may have profound effects on the total biomass in an area that is available to both predators and the fishery.

We initially set out to examine all 4 temperaturedependent krill growth models to get a broader range of predictions of temperature on growth, but ultimately excluded the models of Hofmann \& Lascara (2000), Alonzo \& Mangel (2001), and Candy \& Kawaguchi (2006). Fach et al. (2002) modified the energetics model developed by Hofmann \& Lascara (2000) by assuming that only growth rate was influenced by temperature, following a $Q_{10}$ relationship (increasing exponentially with increasing temperature). The IGR model of Candy \& Kawaguchi (2006) incorporates temperature-dependence in the estimation of the IMP, with IMP decreasing with increasing temperature (estimated by Kawaguchi et al. 2006). These models have no costs associated with increasing temperatures, and predictions are therefore straightforward: higher temperatures result in higher growth rates or more frequent molts, therefore producing larger krill within a cohort. The energetics model of Alonzo \& Mangel (2001) has both costs and benefits to increasing temperature, with increasing metabolic costs and food intake with increasing temperature. However, the model is very sensitive to the temperature-dependent food intake, but the relationship is not based on any empirical studies. We found no studies estimating the effect of temperature on krill filtration rates, and we therefore excluded this model and the models of Candy \& Kawaguchi (2006) and Hofmann \& Lascara (2000) from our analyses.

The current krill-yield model used by CCAMLR to determine krill quotas (Constable \& de la Mare 1996) uses the temperature-independent growth model developed by Rosenberg et al. (1986). Our results suggest that inclusion of temperature-dependent growth into the assessment process may help to predict fluctuations in krill biomass with greater accuracy. However, our review of existing temperature-dependent growth models reveals some limitations, highlighting the need for additional research before such models may be used for management purposes. Even with accurate information on temperature-dependent metabolic costs and filtration rates, using complex energetics models such as those by Hofmann \& Lascara (2000) and Alonzo \& Mangel (2001) may not be practical from a management perspective. Energetics models require precise information on many aspects of krill energetics, particularly in the conversion of energy surplus into growth in length.

In contrast, IGR models, such as those by Atkinson et al. (2006) and Candy \& Kawaguchi (2006), measure growth directly as a function of environmental variables. However, this approach is currently limited by a lack of studies examining growth across all months. Candy \& Kawaguchi (2006) used growth increments measured from December through April and explored a variety of assumptions about growth from May to November. Atkinson et al. (2006) parameterized their model using krill collected in January and February. Although krill were collected across a wide range of temperatures and food concentrations, using the current model to predict growth in other months may be problematic. Research at the Australian Antarctic Division examining krill growth in the laboratory under a variety of temperatures is underway, which will increase our understanding of temperature-dependent krill growth, and thus enable more accurate model predictions (S. Kawaguchi pers. comm.).

A second implication for the management of krill is that our results indicate different model predictions for the different regions explored, with growth positively correlated to temperature around the Antarctic Peninsula and negatively correlated to temperature around South Georgia. Using temperature data averaged over broad spatial scales (such as the south-Atlantic sector of the Southern Ocean) may not accurately reflect local temperature dynamics, resulting in biased estimates of krill growth. Thus, there is a geographic mosaic of krill 
life histories (sensu Thompson 2005), responding differently to temperature changes in the Southern Ocean.

Our results show the potential for considerable variation in the total biomass in a given year resulting just from changes in temperature. However, our estimated years of anomalously low or high biomass (Fig. 8) need not correspond to observed biomass trends. Temporal changes in recruitment, mortality, and transport to a particular region, like South Georgia, are likely driving the overall trends observed in an area. Nevertheless, unfavorable temperatures may exacerbate years when biomass is already low due to decreased abundance in a particular region.

In addition to the effect on growth, a warming Southern Ocean may also impact the reproductive success of krill. Recruitment success is correlated with good sea ice years (in terms of duration and area covered; Siegel \& Loeb 1995), and sea ice cover is closely tied to both air and sea temperature (Clarke et al. 2007). Sea ice cover is predicted to decrease in the near future as global warming continues (Arrigo \& Thomas 2004), and this will likely have a negative impact on krill recruitment (both in the number of years with high recruitment and in the magnitude of individual recruitment events). Therefore, krill biomass will likely be affected by more than just an increase in water temperature.

Although there may be potential violations of our model assumptions (e.g. the depths in the water column occupied or constant food availability) biasing our quantitative results, they will not change the main conclusion and qualitative results (e.g. Fig. 9 in which the patterns at the Antarctic Peninsula and South Georgia are strikingly different). Our examination of existing growth models indicates that temporal changes in temperature in the Southern Ocean may affect individual growth as well as the total biomass available to both predators and the fishery. Moreover, the effects of a potentially warming Southern Ocean on krill biomass will likely be more pronounced in the warmer regions occupied by krill.

Acknowledgements. We thank S. Alonzo and G. Watters for their helpful discussions, C. Simon for graphing assistance, and 4 anonymous reviewers for comments on this manuscript. This work was partially supported by the Lenfest Ocean Program and the Center for Stock Assessment Research, a partnership between the National Marine Fisheries Service Santa Cruz Laboratory and UC Santa Cruz.

\section{LITERATURE CITED}

Alonzo S, Mangel M (2001) Survival strategies and growth of krill: avoiding predators in space and time. Mar Ecol Prog Ser 209:203-217

Arrigo KR, Thomas DM (2004) Large scale importance of sea ice biology in the Southern Ocean. Antarct Sci 16:471-486
Atkinson D, Sibly RM (1997) Why are organisms usually bigger in colder environments? Making sense of a life history puzzle. Trends Ecol Evol 12:235-239

Atkinson A, Siegel V, Pakhomov E, Rothery P (2004) Longterm decline in krill stock and increase in salps within the Southern Ocean. Nature 432:100-103

Atkinson A, Shreeve S, Hirst A, Rotherty P and others (2006) Natural growth rates in Antarctic krill (Euphausia superba): II. Predictive models based on food, temperature, body length, sex, and maturity stage. Limnol Oceanogr 51:973-987

Behrenfeld MJ, O'Malley RT, Siegel DA, McClain CR and others (2006) Climate driven trends in contemporary ocean productivity. Nature 444:752-755

Botkin DB, Saxe H, Araújo MB, Betts R and others (2007) Forecasting the effects of global warming on biodiversity. Bioscience 57:227-236

Candy S, Kawaguchi S (2006) Modelling growth of Antarctic krill. II. Novel approach to describing the growth trajectory. Mar Ecol Prog Ser 306:17-30

Clarke A, Murphy EJ, Meredith MP, King JC, Peck LS, Barnes DKA, Smith RC (2007) Climate change and the marine ecosystem of the western Antarctic Peninsula. Phil Trans R Soc Lond B Biol Sci 362:149-166

Constable AJ, de la Mare WK (1996) A generalized model for evaluating yield and the long-term status of fish stocks under conditions of uncertainty. CCAMLR Sci 3:31-54

Croxall JP, Nicol S (2004) Management of Southern Ocean fisheries: global forces and future sustainability. Antarct Sci 16:569-584

Croxall JP, McCann TS, Prince PA, Rothery P (1988) Reproductive performance of seabirds and seals at South Georgia and Signy Island, South Orkney Islands, 19761987: implications for Southern Ocean monitoring studies. In: Sahrhage D (ed) Antarctic Ocean and resource variability. Springer-Verlag, Berlin, p 261-285

Fach B, Hofmann EE, Murphy EJ (2002) Modeling studies of antartctic krill Euphasia superba survival during transport across the Scotia Sea. Mar Ecol Prog Ser 231:187-203

Fach B, Hofmann EE, Murphy EJ (2006) Transport of Antarctic krill (Euphausia superba) across the Scotia. Part II: Krill growth and survival. Deep-Sea Res I 53:1011-1043

Haddon M (2001) Modeling and quantitative methods in fisheries. Chapman \& Hall/CRC, Boca Raton, FL

Hewitt RP, Demer DA, Emery JH (2003) An 8-year cycle in krill biomass density inferred from acoustic surveys conducted in the vicinity of the South Shetland Islands during the austral summers of 1991-1992 through 2001-2002. Aquat Living Resour 16:205-213

$>$ Hofmann EE, Lascara C (2000) Modeling the growth dynamics of Antarctic krill Euphausia superba. Mar Ecol Prog Ser 194:219-231

Hofmann EE, Klinck JM, Locarnini RA, Fach BA, Murphy EJ (1998) Krill transport in the Scotia Sea and environs. Antarct Sci 10:406-415

Ikeda T (1984) Sequences in metabolic rates and elemental composition (C, N, P) during the development of Euphausia superba Dana and estimated food requirements during its life span. J Crustac Biol 4(Spec No 1):273-284

Jacobs S (2006) Observations of change in the Southern Ocean. Phil Trans R Soc Lond A 364:1657-1681

Kawaguchi S, Candy SG, King R, Naganobu M, Nicol S (2006) Modelling growth of Antarctic krill. I. Growth trends with sex, length, season, and region. Mar Ecol Prog Ser 306:1-15

Levitus S, Antonov JI, Boyer TP (2005) Warming of the world ocean, 1955-2003. Geophys Res Lett 32:L02604, doi: 10.1029/2004 GL021592 
Loeb V, Siegel V, Holm-Hansen O, Hewitt R, Fraser W, Trivelpiece W, Trivelpiece S (1997) Effects of sea-ice extent and krill or salp dominance on the Antarctic food web. Nature 387:897-900

Mackintosh NA (1972) Life cycle of the Antarctic krill in relation to ice and water conditions. Discov Rep 36:1-94

Mackintosh NA (1973) Distribution of post-larval krill in the Antarctic. Discov Rep 36:95-156

Mangel M (2006) The theoretical biologist's toolbox. Cambridge University Press, Cambridge

Meredith MP, King JC (2005) Rapid climate change in the ocean west of the Antarctic Peninsula during the second half of the 20th century. Geophys Res Lett 32:L19604. doi:10.1029/2005GL024042

Miller DGM (1983) Variation in body length measurement of Euphausia superba Dana. Polar Biol 2:17-20

Murphy EJ, Watkins JL, Reid K, Trathan PN and others (1998) Interannual variability of the South Georgia marine ecosystem: biological and physical sources of variation in the abundance of krill. Fish Oceanogr 7:381-390

Nicol S (2006) Krill, currents, and sea ice: Euphausia superba and its changing environment. Bioscience 56:111-120

Nicol S, Stolp M, Cochran T, Geijsel P, Marshall J (1992) Growth and shrinkage of Antarctic krill Euphausia superba from the Indian Ocean sector of the Southern Ocean during summer. Mar Ecol Prog Ser 89:175-181

Nicol S, Forster I, Spence J (2000) Products derived from krill. In: Everson I (ed) Krill biology, ecology and fisheries. Blackwell Science, Oxford, p 262-283

Peck LS, Webb KE, Bailey DM (2004) Extreme sensitivity of biological function to temperature in Antarctic marine species. Funct Ecol 18:625-630

Quetin L, Ross RM (1991) Behavioural and physiological characteristics of the Antarctic krill, Euphausia superba. Am Zool 31:49-63

Quinn T, Deriso R (1999) Quantitative fish dynamics. Oxford University Press, Oxford

Reid K, Croxall JP (2001) Environmental response of upper trophic-level predators reveals a system change in an Antarctic marine ecosystem. Proc R Soc Lond B Biol Sci 268:377-384

Reid K, Croxall JP, Briggs DR, Murphy EJ (2005) Antarctic ecosystem monitoring: quantifying the response of ecosystem indicators to variability in Antarctic krill. ICES J Mar Sci 62:366-373

Rosenberg AA, Beddington JR, Basson M (1986) Growth and longevity of krill during the first decade of pelagic whaling. Nature 324:152-153

Initial editorial responsibility: Howard Browman, Storebø, Norway (until November 5, 2007); Final editorial responsibility: Matthias Seaman, Oldendorf/Luhe, Germany
Ross RM, Quetin LB (1989) Energetic cost to develop to the first feeding stage of Euphausia superba Dana and the effect of delays in food availability. J Exp Mar Biol Ecol 133:103-127

Siegel V (1987) Age and growth of Antarctic Euphausiacea (Crustacea) under natural conditions. Mar Biol 96: 483-495

Siegel V (2000) Krill (Euphausiacea) life history and aspects of population dynamics. Can J Fish Aquat Sci 57(Suppl 3): $130-150$

Siegel V (2005) Distribution and population dynamics of Euphausia superba: summary of recent findings. Polar Biol 29:1-22

Siegel V, Loeb V (1995) Recruitment of Antarctic krill Euphausia superba and possible causes for its variability. Mar Ecol Prog Ser 123:45-56

Smetacek V, Nicol S (2005) Polar ecosystems in a changing world. Nature 437:362-368

Tarling GA, Shreeve RS, Hirst AG, Atkinson A, Pond DW, Murphy EJ, Watkins JL (2006) Natural growth rates in Antarctic krill (Euphasia superba): I. Improving methodology and predicting intermolt period. Limnol Oceanogr 51:959-972

Tarling GA, Cuzin-Roudy J, Thorpe SE, Shreeve RS, Ward P, Murphy EJ (2007) Recruitment of Antarctic krill Euphausia superba in the South Georgia region: adult fecundity and the fate of larvae. Mar Ecol Prog Ser 331:161-170

Thompson JN (2005) The Geographic mosaic of coevolution. University of Chicago Press, Chicago, IL

Trathan PN, Brierly AS, Brandon MA, Bone DG and others (2003) Oceanographic variability and changes in Antarctic krill (Euphausia superba) abundance at South Georgia. Fish Oceanogr 12:569-583

Trathan PN, Murphy EJ, Forcada J, Croxall JP, Reid K, Thorpe SE (2006) Physical forcing in the southwest Atlantic: ecosystem control. In: Boyd I, Walness S, Camphuysen CJ (eds) Top predators in marine ecosystems: their role in monitoring and management. Cambridge University Press, Cambridge, p 28-45

Vaughan DG, Marshall GJ, Connolley WM, Parkinson C and others (2003) Recent rapid regional climate warming on the Antarctic peninsula. Clim Change 60:243-274

Watkins J (2000) Aggregation and vertical migration. In: Everson I (ed) Krill biology, ecology and fisheries. Blackwell Science, Oxford, p 80-102

Watkins JL, Murray AWA, Daly HI (1999) Variation in the distribution of Antarctic krill Euphausia superba around South Georgia. Mar Ecol Prog Ser 188:149-160

Submitted: January 25, 2007; Accepted: November 21, 2007 Proofs received from author(s): March 14, 2008 